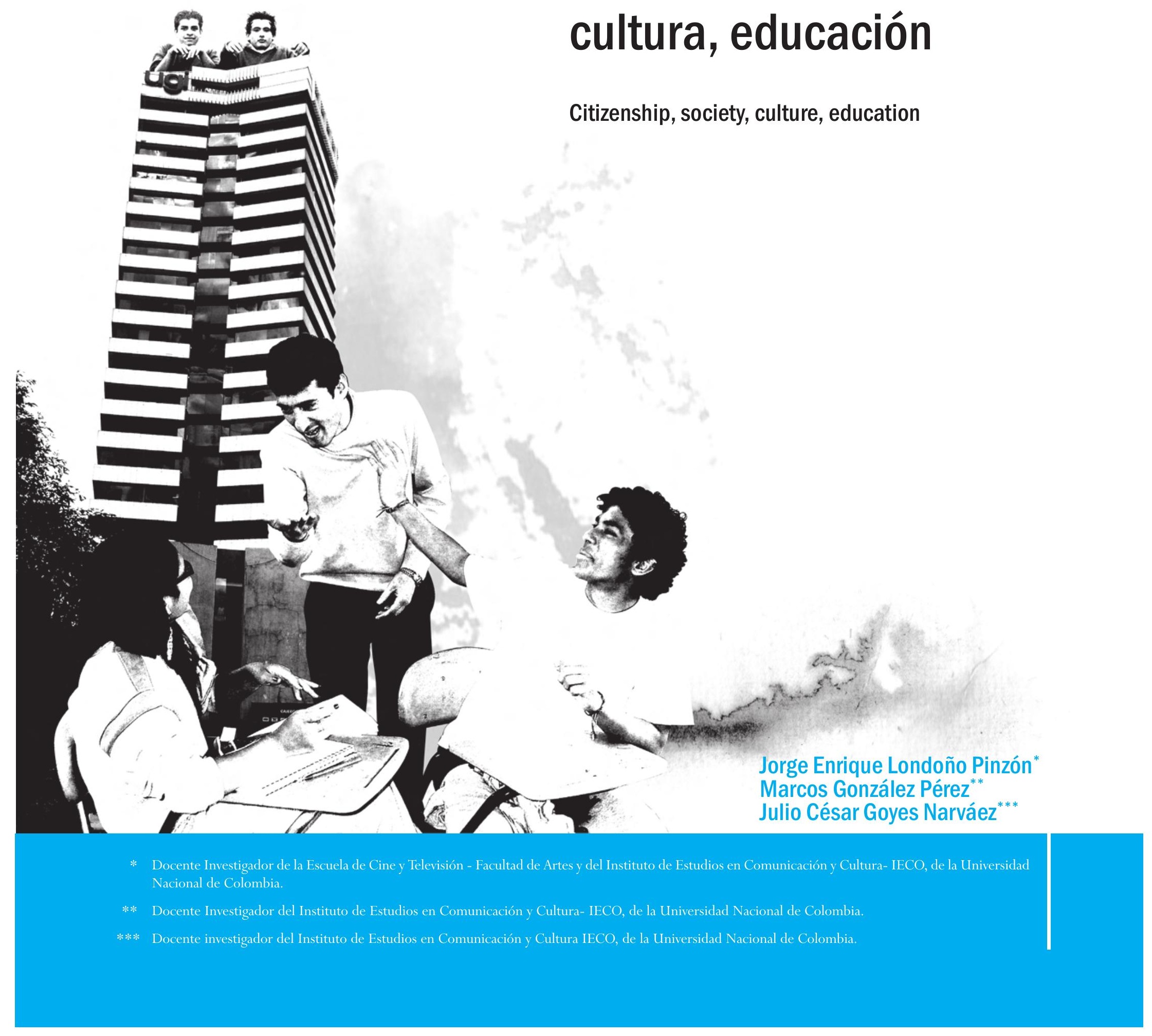

\title{
Ciudadanía, sociedad,
} cultura, educación

\author{
Citizenship, society, culture, education
}

\section{Jorge Enrique Londoño Pinzón Marcos González Pérez Julio César Goyes Narváez ${ }^{* *}$}


Resumen Este artículo se presenta en el marco de la investigación de pedagogía ciudadana que se adelanta en desarrollo del contrato interadministrativo $\mathrm{N}^{\circ} 120$ del 2008, suscrito entre el Instituto para la Investigación Educativa y el Desarrollo Pedagógico (IDEP) y la Universidad Nacional de Colombia (Instituto de Estudios en Comunicación y Cultura, IECO). El texto consta de tres partes, formuladas desde lo social, lo conceptual, lo comunicativo-emotivo y lo educativo, surgidas de los debates realizados internamente por los autores para contribuir a la formulación de criterios teóricos, conceptuales y metodológicos en el diseño de rutas pedagógicas para impulsar procesos de aprehensión de cultura ciudadana.

Palabras Clave: ciudadano, sociedad, cultura, educación, agente social, habitus.

Abstract This article appears within the framework of the Citizen Pedagogy investigation advanced by the IDEP. The text consists in three parts taking in account the social, the conceptual, the communicative-emotional and the educative view, as a result of intern debates realized by the authors to contribute to the formulation of theoretical, conceptual and methodological criteria in the design of pedagogical ways to impulse processes of apprehension of citizen culture.

Keywords: citizen, society, culture, education, social agent, habitus. 


\section{El ciudadano: agente social Por Jorge Enrique Londoño Pinzón}

Los "sujetos" son en realidad agentes actuantes y conscientes dotados de un sentido práctico (...), de un sistema adquirido de preferencias, de principios de visión y de división (lo que se suele llamar un gusto), de estructuras cognitivas duraderas (que esencialmente son fruto de la incorporación de estructuras objetivas) y de esquemas de acción que orientan la percepción de la situación y la respuesta adaptada. El habitus es esa especie de sentido práctico de lo que hay que hacer en una situación determinada, lo que en deporte se llama el sentido del juego, el arte de anticipar el desarrollo futuro del juego que está inscrito en punteado en el estado presente del juego ${ }^{1}$.

La noción del ciudadano como agente social es insoslayable en la búsqueda de criterios teóricos, conceptuales y prácticos para la formulación de políticas y metodologías dirigidas a la educación ciudadana.

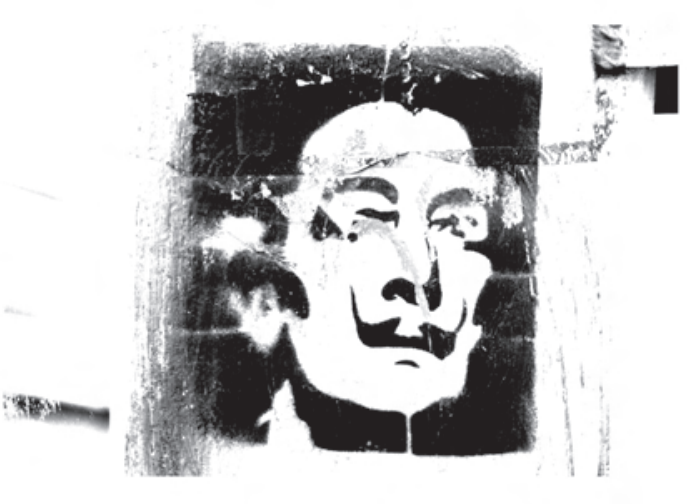

Más allá de la aclaración de este concepto relacional $\tan$ importante y tan complejo, elaborado a lo largo de muchos años de trabajo por el sociólogo francés, nuestra pregunta orientadora, cuando nos preocupa la formación del ciudadano, debe centrarse en tratar de aclarar qué factores influyen en la adquisición de los habitus de comportamiento ciudadano y en las personas, instituciones o actos rituales que intervienen en la inculcación de "estos principios generadores de prácticas distintas y distintivas" en tanto implican sujetos activos, como pueden ser la familia, la escuela, la Iglesia, las organizaciones culturales y deportivas, la tribu, el "parche", la pandilla o los media, agentes que interactúan con los sujetos/agentes sociales en la conformación de sus "principios generadores y unificadores", ya sea en un proceso formativo o en procesos continuos de adaptación.

1 Bourdieu, Pierre. La distinción, criterio y bases sociales del gusto, Taurus, 1998, p. 40.

2 Londoño, Jorge. "Las máscaras del diablo", estudio sobre los agentes inculcadores de habitus [CD interactivo], Bogotá, Universidad Nacional, 2004. 
mixturas, de espejos trizados, de hibridaciones culturales y de imaginarios que han dado paso a numerosas investigaciones sobre la ciudad y sus habitantes en los últimos treinta años. Uno de los objetos de estudio entre estas mezclas culturales es la presencia de los medios masivos de comunicación, especialmente la televisión, su programación y sus mediaciones, investigaciones que han tratado de explicar los procesos de modernización y posmodernización en Colombia, sin dejar de lado la influencia cultural, no sólo la guerra, que generó el narcotráfico, la abundante y efímera circulación de grandes cantidades de dinero y la desvalorización total de la vida.

Durante este proceso se han dado cambios importantes en cuanto a la estructura familiar, el peso de la "escuela" en la formación e inculcación de sistemas de percepción y clasificación, la descentralización y poder hegemónico

Entre los retos que deben enfrentar los responsables desde el sector educativo de la formulación y ejecución de estas políticas se encuentra establecer en cuánto contribuye la escuela — es decir, las instituciones educativas - en los procesos de conformación ciudadana, frente a otros agentes inculcadores de habitus².

Hasta la mitad del siglo XX los agentes inculcadores de habitus en Colombia estuvieron altamente centrados en la familia, la Iglesia, la escuela, los partidos políticos, y en el Estado.

El proceso de desplazamiento del campo a la ciudad iniciado con la denominada "Violencia" (1948-1954), y que entre 1975 y 1985, con las sucesivas "guerras de turno" transformó el país de rural a urbano, invirtiendo las cifras para el año 2000 — setenta por ciento urbano y treinta por ciento rural- originaron un proceso de sobre la información, la escuela fuera de la escuela y la inculcación de "sentido práctico" a través de medios de comunicación masivos como la televisión, la Internet y demás adelantos tecnológicos actuales, como la telefonía móvil.

Estas investigaciones han establecido los parámetros para explicar las especificidades de los procesos culturales en los países de América Latina, como Colombia: “...lo cultural entendido no sólo como conjunto de productos sino como matrices y prácticas de conocimiento y comportamiento; lo popular como modo de existencia de competencias culturales diferentes a la hegemónica" ${ }^{3}$.

"Ya señalamos la crisis de las instituciones tradicionalmente socializadoras de imaginarios, interpretaciones, clasificaciones sociales, valores y conductas, como la familia, la escuela y los partidos políticos" ${ }^{\text {. }}$.

3 Martín-Barbero, Jesús. Televisión y melodrama, Bogotá: Tercer Mundo Editores, 1992, p. 20.

4 Jaramillo, Jaime Eduardo. "Formas de sociabilidad y construcción de identidades en el campo urbano popular", en Cultura, medios y sociedad, Bogotá: CES, Universidad Nacional de Colombia, 1998, p. 206. 
En Colombia se dio un caso particular de agente inculcador de habitus: con la combinación de escuela/ Iglesia, podríamos decir que las primeras instituciones educativas eran regidas por comunidades religiosas.

Para citar un ejemplo moderno, vale la pena recordar la aparición, hacia 1950, de Radio Sutatenza (Acción Cultural Popular, ACPO) y su proyecto educativo Escuelas Radiofónicas - Radio Sutatenza (Boyacá, Colombia). Su lema era la educación a través del uso combinado de todos los medios, interacción cara a cara, casi mediática, a través de la radio, y hacia el final algunas aproximaciones a la televisión y al video, e interacción mediática a través de impresos como El campesino —periódico semanal_, cartillas, Biblioteca Básica Campesina, discos y casetes de audio y correspondencia con los campesinos.

Con la formación de multiplicadores-tutores (el "auxiliar inmediato"), Radio Sutatenza alcanzó su época de oro entre 1970 y 1980 y "enseñó" a leer y escribir utilizando la radio, e inculcó "esquemas de percepción” religiosos, sociales y políticos. Los alcances de su metodología exitosa obligan a evaluar sus principios y procedimientos y tenerlos en cuenta para formular proyectos de pedagogía ciudadana.

Pero actualmente el centro de influencia educativa se desplaza hacia las empresas mediáticas, como precisa J. B. Thompson, quien, entre otros aspectos, ve cómo:

Mientras que la actividad simbólica es una característica penetrante que se expande por doquier de la vida social, existe, a pesar de ello, un conjunto de instituciones que han asumido un papel histórico particularmente importante en la acumulación de los medios de información y de comunicación.

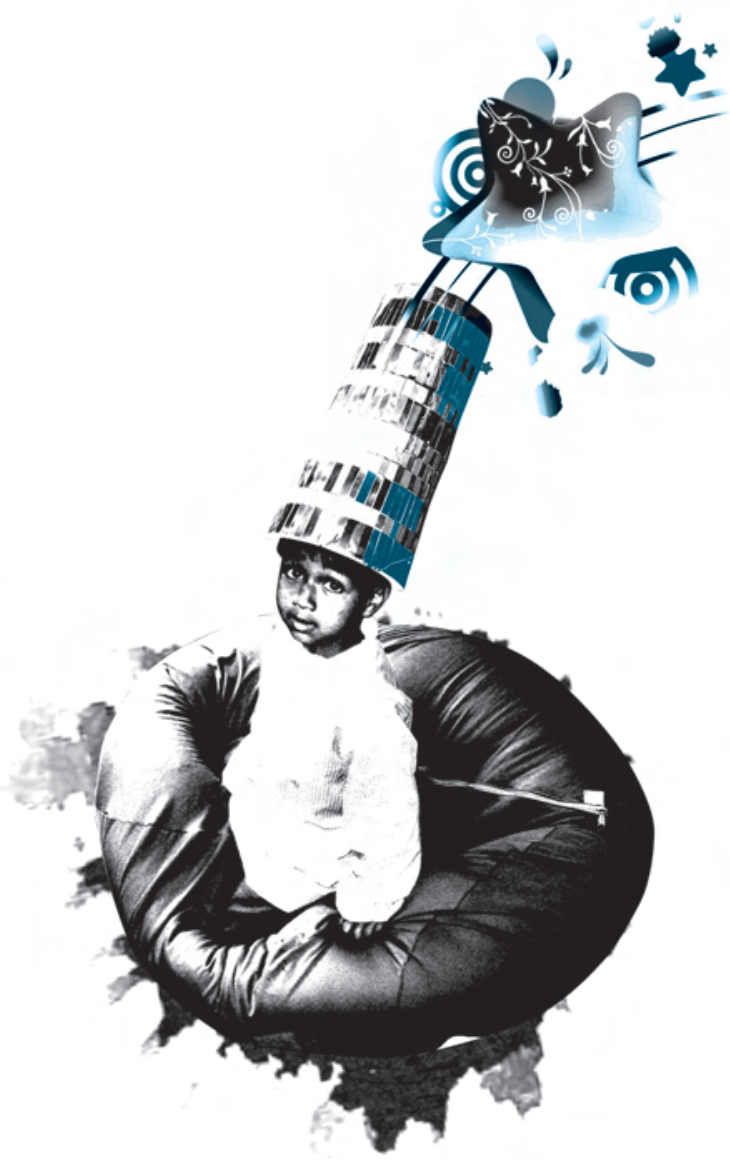


Estas incluyen a las instituciones religiosas, que se ocupan básicamente de la producción y difusión de formas simbólicas relacionadas con la salvación, los valores espirituales y otras cosas mundanas; (las) instituciones educativas que se ocupan de los contenidos simbólicos adquiridos (o conocimiento) y de la inculcación de habilidades y competencias; y las instituciones mediáticas, que se orientan hacia la producción y difusión generalizada a gran escala de formas simbólicas en el espacio y en el tiempo ${ }^{5}$.

Teniendo en cuenta los diversos contextos sociales que rodean al escolar de hoy, ¿cuál es el alcance de los esfuerzos de las instituciones educativas para formar ciudadanos?

Su papel como agente educador debe tener en cuenta esta realidad e idear estrategias pedagógicas que transciendan los muros de la escuela y se inserten en los procesos sociales donde hacen presencia organizaciones juveniles, videojuegos, películas, televisión, cable, Internet, móviles, y un interminable etcétera que va al ritmo del desarrollo tecnológico.

Hace cuarenta años Alejo Carpentier planteaba que el estilo de las ciudades latinoamericanas era no tener estilo, y con el tiempo esos desafíos existentes se iban haciendo estilos ${ }^{6}$.

Hoy las ciudades son el centro del desarrollo de la cultura y su estilo sigue un largo proceso de definición: “... la ciudad es sobre todo el desconcierto y el espacio en que se pierde la memoria... la ciudad identificada como lugar de lo artificial y lo complejo", porque supera lo rural y simple ${ }^{7}$.

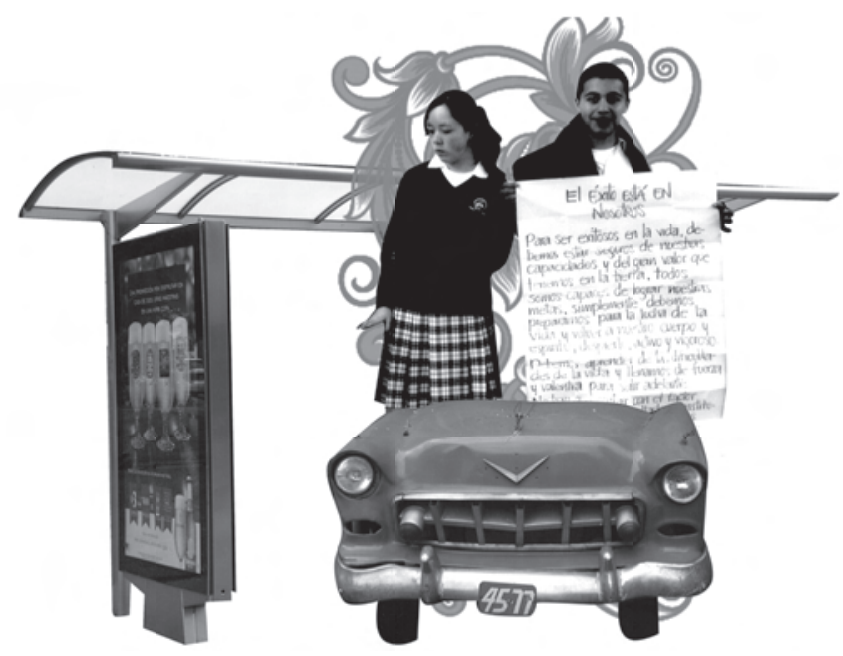

5 Thompson, John B. Los media y la modernidad, Barcelona: Ediciones Paidós, 1998, p. 35.

6 Carpetier, Alejo. Tientos y diferencias, Buenos Aires: Calicanto Editorial, 1967, p. 18.

7 Martín-Barbero, Jesús. De los medios a las mediaciones, Barcelona: Editorial Gustavo Gili, 1987, pp. 182-209. 
Es indudable que el desbordamiento de ciudades como Bogotá, México D. F. o Sao Pablo ha generado un modelo propio, cuna de la hibridación de las culturas, creando otras. Nueva cultura, por ejemplo, la del barrio que se origina en: "una ciudad desbordada en su geografía y en su moral: las situaciones de hecho - invasiones de terrenos en la periferia para habitar y de las calles del centro que permitan sobrevivir- reproducen nuevas fuentes de derecho reconocidas o permitidas por un Estado a su vez desbordado" ${ }^{\text {. }}$.

Las culturas campesinas tradicionales ya no representan la parte mayoritaria de la cultura popular. En las últimas décadas las ciudades latinoamericanas pasaron a contener entre el 60 y el 70 por ciento de los habitantes ${ }^{9}$.

...Y la masa siguió invadiendo todo. Porque en medio de su ignorancia de las normas y del desafío que su sola presencia entrañaba, su deseo más secreto era acceder a los bienes que representaba la ciudad ${ }^{10}$.

Por una parte, la presencia desbordante de la masa impone sus costumbres, sus formas de comportamiento (habitus disímiles y difusos), haciendo perder vigencia a la consideración de lo cultural como lo selecto, lo culto... "visión culta de la cultura — por lo demás absurda en una época de primacía de las formas y de los contenidos de la cultura de masas, de los medios de comunicación y de la industria cultural" ${ }^{11}$ —
Por otra parte, también se desvanece la concepción de los "folcloristas románticos", que ven en el folclor lo auténtico y válido culturalmente, necesario de preservar y difundir. "Aun en zonas rurales, el folclor no tiene hoy el carácter cerrado y estable del universo arcaico, pues se desarrolla en las relaciones versátiles que las tradiciones tejen con la vida urbana, las migraciones, el turismo, la secularización y las opciones simbólicas ofrecidas tanto por los medios electrónicos como por nuevos movimientos religiosos o por la reformulación de los antiguos" ${ }^{\prime 2}$.

La cultura adquiere entonces otras dimensiones, especialmente la de la heterogeneidad, la pluralidad y su coexistencia. En este punto coinciden Martín, Bruner y Canclini, autores que proponen un mapa para el estudio, análisis y transformación de nuestra realidad cultural:

En el caso de América Latina, como decíamos, el motor de la modernidad — el mercado internacional_ provoca y luego refuerza un incesante movimiento de heterogeneización de la cultura, poniendo en juego, estimulando y reproduciendo una pluralidad de lógicas que actúan todas ellas entrecruzándose ${ }^{13}$.

Hemos pasado de sociedades dispersas en miles de comunidades campesinas con culturas tradicionales locales homogéneas en algunas regiones con fuertes raíces indígenas, poco comunicadas con el resto de cada nación, a una trama mayoritariamente urbana, donde se dispone de una oferta simbólica heterogénea, renovada

8 Ibíd., p. 215.

9 García Canclini, Néstor. Culturas híbridas, México: Editorial Grijalbo, 1989, p. 203.

10 Martín-Barbero, op. cit., p. 172.

11 Brunner, José Joaquín. América Latina, cultura y modernidad, México: Editorial Grijalbo, 1992, p. 173.

12 García Canclini, op. cit., p. 203.

13 Bruner, Joaquín, op. cit., p. 181 


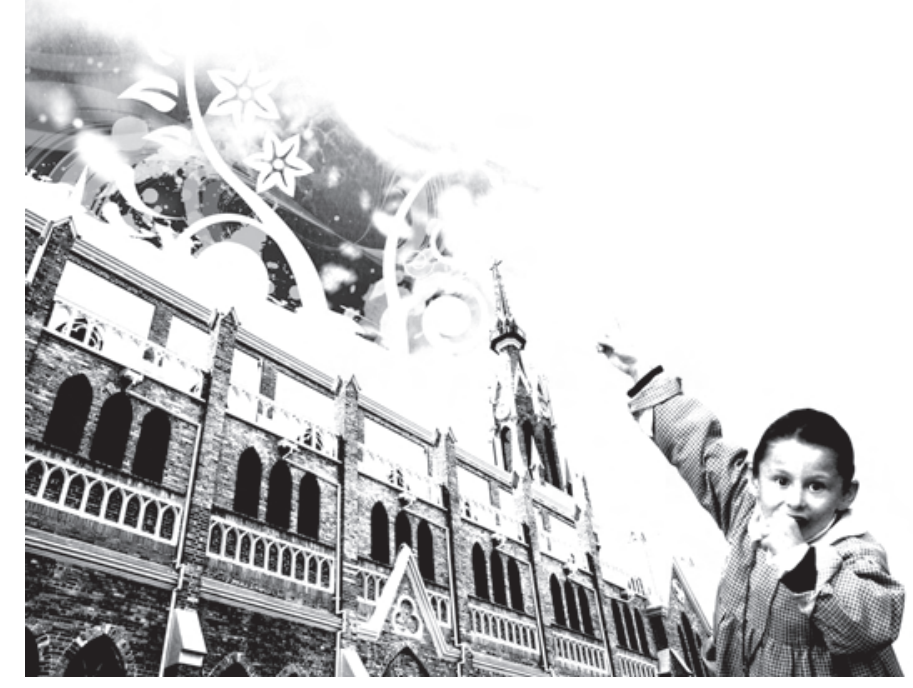

por una constante interacción local con redes nacionales y transnacionales de comunicación ${ }^{14}$.

[...] la verdad cultural de estos países: el mestizaje, que no es sólo el hecho racial del que venimos, sino la trama hoy de modernidad y discontinuidades culturales, de formaciones sociales y estructuras del sentimiento, de memorias e imaginarios que revuelven lo indígena con lo rural, lo rural con lo urbano, el folklore con lo popular y lo popular con lo masivo ${ }^{15}$.

Estos planteamientos rescatan lo popular, realizando un análisis histórico desde el surgimiento mismo de los conceptos de pueblo y masa en 1835, según Martín, hasta llegar a una reubicación de lo popular en cuanto a manifestación diferente a la hegemónica: "Y estamos descubriendo estos últimos años que lo popular no habla únicamente desde las culturas indígenas o las campesinas, sino también desde la trama espesa de los mestizajes y las deformaciones de lo urbano y lo masivo".
Junto con la descentración del conocimiento de la escuela, la pérdida de hegemonía de la Iglesia católica frente a nuevas Iglesias, la pérdida de credibilidad en los partidos políticos, la desmembración de las comunidades y de las familias por el desplazamiento forzado, han generado otros medios de transmisión de formas de pensamiento y comportamiento.

Esos estudios han sentado las bases para demostrar que existen en Colombia otros agentes persuasivos distintos de los hegemónicos en la primera mitad del siglo XX, porque la situación de cambio social ha dado paso a otro tipo de núcleos sociales, "escuelas de formación", que cumplen las funciones de inculcación de "estructuras de percepción y valoración”.

Por la teoría de la recepción cultural se puede comprender que la asimilación de imágenes, interpretaciones, valores, y prácticas institucionalizadas, vehiculizadas desde el Estado, las Iglesias, los medios

14 García Canclini, op. cit., p. 265

15 Martín-Barbero, Jesús. De los medios a las mediaciones, Barcelona: Editorial Gustavo Gili, 1987, p. 10. 
de comunicación, etc., es resignificada y recreada en función de matrices sociales y culturales previas. La pertenencia a una familia, el origen en único, la territorialidad barrial, las adhesiones religiosas, culturales, etc., crean identidades restringidas, a algunas de las cuales nos referiremos luego, que funcionan como "comunidades de sentido"16.

Sus observaciones y planteamientos se abren a la posibilidad del diálogo con otros investigadores, pero centrando su mirada en los países latinoamericanos y desde ellos avanzando en las representaciones de las realidades de estas problemáticas bajo una perspectiva interna que tiene en cuenta su diferencia con los modelos investigativos elaborados sobre otras realidades.

Es importante observar que las obras de Bourdieu están centradas en la sociedad francesa, como él mismo lo enfatiza, advirtiendo sobre el uso descontextualizado de los conceptos.

Una alerta sobre el alcance de las investigaciones de Pierre Bourdieu para América Latina está citada en "Formas de sociabilidad y construcción de identidades en el campo urbano popular":

Con todo, el reproductivismo bourdieano adscrito al estructuralismo, paradigma que el autor ha buscado trascender sin lograrlo plenamente, se nos revela fecundo en un primer nivel de análisis, pero insuficiente, pensando desde el específico contexto latinoamericano, para comprender la dinámica del campo popular, la red, la recepción, la resignificación y la recreación desde sus matrices societarias y culturales de elementos económicos, formas de sociabilidad y rasgos culturales de la sociedad hegemónica de los textos, sonidos e imágenes de los mass media, así como el sincretismo que establece, en el marco urbano, entre las diversas subculturas regionales, campesinas, étnicas, etc. $[\ldots]$ En este campo ambiguo, no reductible a las categorías antinómicas sumisión-resistencia, el sistema de Bourdieu se nos revela insuficiente ${ }^{17}$.

Estos conceptos sólo cobran sentido después de un proceso de investigación que permita, incluso, crear antinomias diferentes a las de "sumisión-resistencia" que rompe la figura del latino.

El complejo proceso de adquisición de habitus de comportamiento ciudadano sólo puede darse en tanto se ejerce la ciudadanía interactuando con los otros ciudadanos, en los diversos espacios que conforman la ciudad.

Tratar de comprender el papel que juega la institución educativa en los procesos de formación ciudadana y su relación (su posición en el campo) con los otros agentes inculcadores existentes en la ciudad, es indispensable para la comprensión de los procesos de formación ciudadana y la formulación de directrices educativas y metodologías para impulsar los valores de convivencia pacífica, de cuidado del medio ambiente, de la conservación y desarrollo del patrimonio cultural material e inmaterial, y de la vigilancia, la observación y la práctica de los procedimientos convenidos por todos.

El ejercicio de la ciudadanía se da plenamente en la ciudad fragmentada, donde coexiste la mixtura de culturas en un proceso hacia la interculturalidad, con un campo de interacciones sociales que en diversas esferas de la vida parten de olvidar, ignorar o desconocer un derecho fundamental esencial para los demás, el valor de la vida y el derecho a conservarla.

16 Jaramillo, Jaime Eduardo, op. cit., p. 177.

17 Jaramillo, Jaime Eduardo, op. cit., p. 178. 
puede considerarse la cultura esa urdimbre, y que el análisis de la cultura ha de ser por lo tanto, no una ciencia experimental en busca de leyes, sino una ciencia interpretativa en busca de significaciones" ${ }^{20}$.

En este sentido interpretar la realidad significa buscar las significaciones que la población escolar (estudiantes, maestros y padres de familia) han venido construyendo a través de simbolizaciones muy propias de las cotidianidades urbanas.

Se trata entonces de comprender que la "educación intercultural se inscribe como discurso pedagógico de la diferencia y la identidad" ${ }^{21}$ y que el objeto de la pedagogía intercultural debe ser, además de las propias instituciones educativas, "los espacios de educación y los discursos pedagógicos en tanto que configuraciones de unas formas concretas de identidad"22.

Es claro entonces que las reivindicaciones comunitarias, en este caso el respeto de los derechos colectivos y la apropiación de los espacios de la ciudad, son ejes de la articulación que se debe buscar entre convivencia y tejido social. Así, la interculturalidad nos remite a la búsqueda de la diversidad, "a la diferencia establecida desde lo cultural y a la forma en que cada sujeto articula lo identitario con la sociedad de la que forma parte"23, principalmente, porque las culturas "son maneras de interpretar y significar la realidad" y, dado que son simbólicas, "están sujetas a influencias, préstamos y cambios de todo tipo, adaptativos unos, negativos otros" ${ }^{24}$.

Por otra parte, tomando en cuenta el papel de las disciplinas y de la multidisciplina en la aproximación a un objeto de estudio, la formulación de políticas y metodologías para la formación ciudadana debe construir el campo de la interdisciplinariedad, entendida como el espacio en el cual se desborda el simple encuentro de las disciplinas y más bien utiliza su presencia para intentar una síntesis entre los métodos de cada una de ellas. La interdisciplina no abandona la unidad del objeto y más bien muestra su complejidad. La interdisciplina "no puede tratarse como un método sino como una forma estratégica de abordar el conocimiento, el cual a medida que avanza debe inventar senderos, tomar caminos no conocidos en la búsqueda de resolver dificultades, recurrir a otras disciplinas de las cuales no se tomaba en un principio su aporte de tal manera que la interdisciplinariedad es el lugar geométrico donde se manifiesta el conjunto de esas estrategias" ${ }^{25}$.

20 Geertz, Clifford. La interpretación de las culturas, Barcelona: Gedisa, 1989, p. 20

21 Ytarte, Rosa Marí, op. cit., p. 25.

22 Ibíd., p. 25

23 Ibíd., p. 26

24 Ibíd., p. 19

25 Ver González Pérez, Marcos. La investigación interdisciplinaria, Bogotá: Editorial Magisterio, 1998, p. 7, y Resweber, Jean Paul.

La Méthode interdisciplinaire, París: PUF, 1981. 
Este concepto debe ser aplicado en dos sentidos: por una parte, es evidente que el proceso de construcción de cultura ciudadana es emprendido por profesionales, cuyos discursos provienen de diversas disciplinas que deben empeñarse en encontrar conectores conceptuales adecuados para abordar el acompañamiento del proceso en su conjunto y en sus especificidades. Por otra parte, por los propios actores centrales del aprendizaje, principalmente, porque desde una perspectiva intercultural "la educación debe pensar en diseñar prácticas educativas capaces de generar distintas narraciones e identidades" 26 .

Los avances conceptuales, al reflexionar sobre las ciudadanías, han podido determinar que uno de los elementos esenciales en la construcción de una cultura ciudadana debe tener en cuenta como uno de sus ejes la idea de convivencia, noción que pretende superar un establecimiento de normas, trátese de normas mínimas o de normas morales, para coexistir. "La articulación de la convivencia en sociedades cada vez más multiculturales es uno de los desafíos más importantes que tienen las sociedades del mañana" 27 , y puede orientar los programas de pedagogía ciudadana.

En este sentido, vale la pena apuntar a profundizar, en una relación teórico-práctica, nociones tales como el "reconocimiento de las diferencias" o "las relaciones de reconocimiento recíproco", lo cual nos guía hacia una discusión del significado de las condiciones jurídicopolíticas indispensables para la aprehensión de cultura ciudadana, pero también para pensar la construcción de ciudadanías o en las perspectivas de avistar un buen morador de la ciudad, en el marco de procesos de aprendizajes de cohesiones sociales en sociedades fragmentadas.

Así, el significado de nuestra acción de acompañar procesos de formación ciudadana nos obliga a entender que más allá de todo discurso moral o cultural se impone una construcción de ciudadanía desde la esfera de lo social, dado que se trata de intervenir en dispositivos sociales que se pretenden transformar.

Si consideramos que los moradores de Bogotá no tienen realmente prácticas de cultura ciudadana, el sentido de trabajar la interculturalidad debe hacerse teniendo en cuenta los valores dominantes de los dispositivos sociales que se oponen a otra serie de valores que no han sido reconocidos o aprehendidos por los colectivos o comunidades bogotanas. De esa manera, el aprendizaje de cultura ciudadana "debe estar estrechamente asociado a la situación concreta que vive el alumno" ${ }^{28}$ y ésta es determinada tanto por las relaciones sociales como por relaciones culturales; con base en ello, este proceso sirve para que "los sujetos sociales transformen el mundo al mismo tiempo que se transforman" 29 .

Podemos tener en cuenta que la ciudadanía relacionada con el tema de construcción de pedagogía ciudadana en el nivel escolar, en una ciudad como Bogotá, tiene en los conceptos de igualdad, diversidad e identidad, tres claves para su comprensión.

26 Rotger, Antoni, "Prólogo", en Ytarte, Rosa Marí, op. cit., p. 19.

27 Silveira; Héctor, y otros. Identidades comunitarias y democracia, Barcelona: Editorial Trotta, 2000, p. 4.

28 Couedel, A.; Blondeau, N. Pedagogía de proyecto, interculturalidad y dinámica social, p. 3.

29 Couedel, A.; Blondeau, N. Pedagogía de acción y de transformación social, p. 4. 


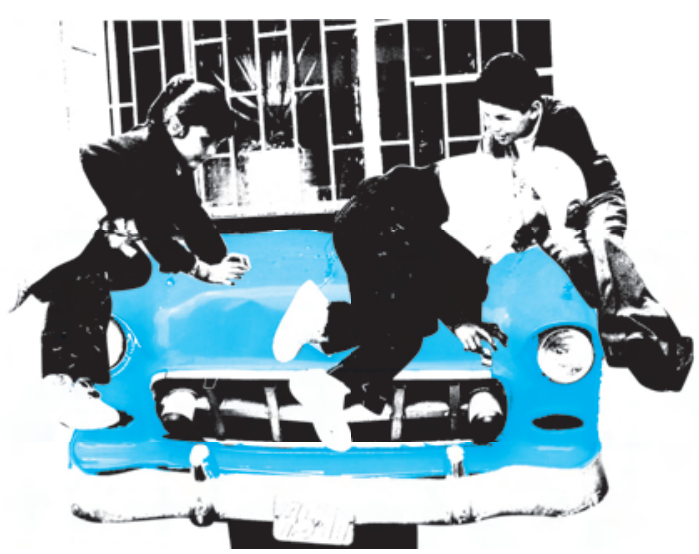

El primero, basado en el reconocimiento social de los moradores, mediante el cual se propician ejercicios de inclusión tanto desde el Estado como por las acciones de las propias comunidades ${ }^{30}$.

El segundo, el de la diversidad, aceptado como norma constitucional, pero que adquiere validez sólo cuando se convierte en una práctica permeada por el reconocimiento social.

La identidad se relaciona con las actitudes y comportamientos de pertenencia hacia los espacios que brinda la ciudad, comprendidos los territoriales ${ }^{31}$, pero también los mentales, en el sentido de considerar la ciudad como su lugar referencial de hábitat.

No se trata de crear una comunidad política, en el sentido de pertenecer a una nación o a una ciudad, sino de establecer una serie de articulaciones de convivencia para un mejor aprovechamiento de ésta.
Dichos elementos deben hacer parte de la problemática que se requiere abordar en el aprendizaje ciudadano, dado que la experiencia hasta ahora vivida por la mayoría de los moradores de la capital es la de no tener un apego real a la ciudad.

En todo caso, “...la perspectiva intercultural, basada en los conceptos de ciudadanía y pluralidad, requiere una práctica educativa en la que la identificación con estos principios no signifique la renuncia a las formas particulares de identidad" 32 .

Significa esto que las raíces culturales aprehendidas por los moradores que vienen de la periferia a la capital pueden, en muchos casos, mantenerse, pero en otros, sentir las interferencias de la vivencia capitalina por la acción de entrecruzamiento con otras prácticas culturales. He ahí otro de los retos del proceso: verificar la construcción de una cultura del morador actual de la ciudad que puede haber creado un nuevo bogotano, poco observable en los comportamientos de los adultos pero posiblemente expreso en la población infantil y juvenil.

\footnotetext{
30 Un buen ejemplo de estas construcciones en la ciudad capital se puede ver en los procesos festivos escolares y en los comunitarios. Ver: González Pérez, Marcos, El mapa festivo de Bogotá, Ediciones Intercultura, 2007.

31 Hobsbawm, Eric, "Identidad”, en Silveira, Héctor y otros, op. cit., p. 48: "La identidad primordial que la mayoría de nosotros hemos elegido (...) es la del estado territorial, es decir, una institución que establece un principio de autoridad sobre cada uno de los habitantes de un trozo del mapa”.

32 Ytarte, Rosa Marí, op. cit., p. 182.
} 
No se trata de encontrar una sociedad homogénea en una ciudad fragmentada socialmente, pero sí de intentar crear condiciones de cohesión social o comunitaria orientadas al "bien común" la pertenencia o identidad es uno de los imaginarios esenciales.

\section{Los elementos comunicativos y emotivos Por Julio César Goyes Narváez}

Los conceptos de interculturalidad e interdisciplinariedad toman aquí matices derivados hacia la comunicación, especialmente la audiovisual, y a la metodología o campo experiencial de frontera. La cultura audiovisual es interdisciplinaria y fronteriza e igualmente urbana; es decir, la caída de los macrorrelatos o metarrelatos (cultura ciudadana, planificación urbana, políticas públicas, etc., como todas la disciplinas que se refieren a totalidades y, digamos que, a generalidades) dieron paso a las redes locales y a las tramas singulares. Una pregunta primaria podría ser: ¿con qué mirada, experiencia y metodología podemos conocer el mundo ya no totalizado sino fragmentado de la ciudad?

En todo caso, esta pregunta, si bien no tiene una respuesta definitiva, sí posee un principio, una forma de comprenderla, de pensarla, de imaginarla: podemos acercarnos a la ciudad fragmentada, a su trama ciudadana, desde los fragmentos narrativos, esto es, desde las ciudades experimentadas, imaginadas, soñadas, padecidas, disfrutadas, repudiadas...

Proponemos abrir las interrogaciones por esos conceptos macro, aunque eso no signifique anclarse para esperar la respuesta: pedagogía, infancia, escolaridad, ciudad, ciudadanía, cultura, comunicación, saber, poder, interdisciplinariedad, interculturalidad, deberes, derechos, etc., ¿vale la pena insistir en un esencialismo caduco?, ¿hasta dónde podemos definir esos términos, acaso no hay suficiente ilustración sobre ello? y, en cambio: ¿Qué hay de la experiencia, la existencia, de la acción y la práctica? ¿Cómo acudir a un proceso y una experiencia para llegar al concepto? ¿No es la misma ciudad, es decir, su experiencia, la que nos enfrenta a lo real por vía imaginaria? ¿Y no es justamente la infancia la que hace memoria y metaforiza el olvido de esa ciudad-barrio, ciudad-casa, ciudad-calle, en la que acontece? Sin embargo, y en todo caso, experiencia no existe si no hay simbolización, lo cual quiere decir que hay que contar lo ocurrido y luego volver a contarlo.

Digamos algo más, para seguir contribuyendo a la con-fusión: tal vez basten los conceptos que ya hay, quizá lo que deseamos sean experiencias. De otra manera: acaso los procesos, los desempeños ciudadanos nos lleven a escapar a algunos conceptos, pues si no están, habrá entonces que darles nombre, construirlos.

33 El término es de Hobsbawm, Eric, "Identidad”, en Silveira, Héctor y otros, op. cit., p. 49. Además, según el autor, “...la razón obvia por la cual esto es así es que, desde que el mundo es mundo, ningún territorio — cualquiera que sea su tamaño— ha sido habitado por una única población homogénea, ya sea cultural, étnica o de cualquier otros aspecto”, ibíd., p. 50. 


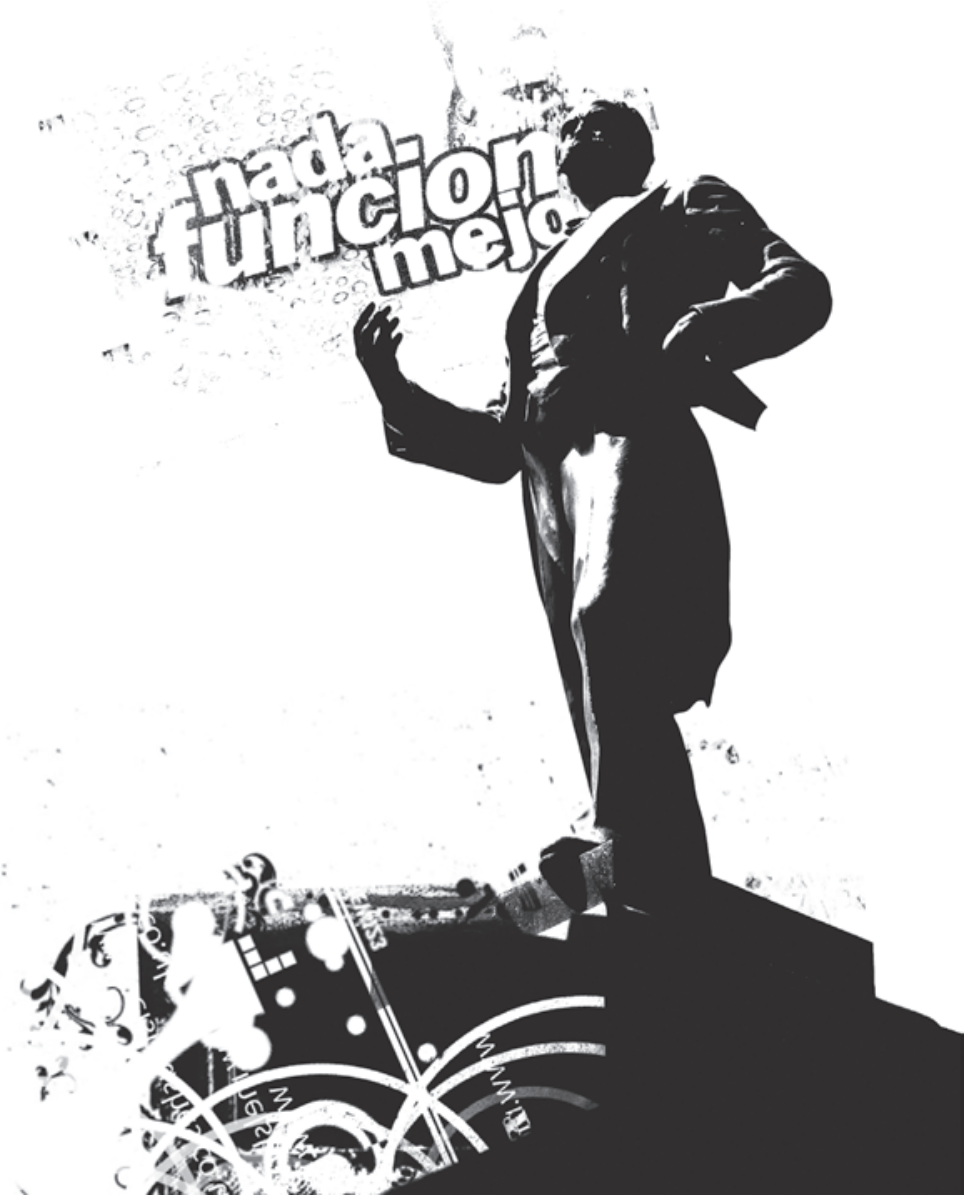

La comunicación es intercultural. La comunicación, tal como la concebimos hoy, no se restringe al esquema instrumental emisor-mensaje-receptor, tampoco a la circulación de información; ante todo, como lenguaje (verbal y no verbal) que la constituye, es experiencia. La comunicación es mucho más que intercambio de mensajes; es, sobre todo, una construcción de sentido interactiva e intercultural. Esta interculturalidad es interdisciplinariedad, donde los conocimientos, las prácticas y los valores toman forma crítica y creativa, superando las prácticas comunicativas y educativas homogeneizantes y excluyentes construidas alrededor de la cultura occidental como único referente válido.

La interculturalidad se hace posible cuando la comunicación entra en sinergia con los ámbitos cognitivos, emotivos y situacionales. Aclaremos, entonces, que la comunicación que nos interesa tiene especificidad audiovisual, puesto que ésta es un acto cognitivo y emotivo al tiempo, y como acto tiene presencia performática. Todo modo de ver es la posibilidad de construir una mirada, de empoderar esa mirada; no obstante, un modo de ver también es una forma de no ver, de ocultar. La percepción es, por definición, selectiva.

Cuando percibimos estamos ya pensando, sostendría Rudolf Arheim, y lo hacemos porque la percepción selecciona y combina al unísono. De suerte que vemos desde un punto de vista, desde un prejuicio, un saber-poder o un podersaber. Se trata de revalorar la emoción, el sentimiento y la expresión que hasta hace poco se han tenido como reacciones irracionales, poco fiables para el conocimiento; por esto la educación no se ha apoyado en la interactuación de la intuición con el intelecto, la imagen con el concepto, la imaginación con la razón ¿Y dónde queda el cuerpo, el otro gran excluido del discurso educativo?, tema que merece capítulo aparte y que no puede dejarse de lado al considerar el ejercicio de la ciudadanía y la pedagogía ciudadana.

La ciudad audiovisual es cinética (movimiento), cinésica (gestualidad), proxémica (espacio como construcción cultural), telemática (redes y servicios comunicacionales), informática (información), poética (especificidad imaginaria, 
experiencia estética), cinematográfica (cine y fotografía), plástica (pintura y afines), errática (errante, viajera), acusmática (la voz sin imagen, sin reconocer la fuente), narrativa (relatos), performática (sentidos en proceso, actuación, transformación, participación, choque, experiencia, etc.) y demás.

Dijimos cognición, auto-conciencia, conciencia e inconsciencia de nuestras identidades y diferencias culturales, de nuestras teorías y experiencias comunicativas. La interculturalidad abandona la teoría general, su racionalismo y empirismo, y busca las articulaciones de la cultura, pues considera que la realidad es una construcción.

La realidad social no tiene existencia con independencia de los actores y las teorías que le dan forma, y del lenguaje, que permite conceptualizarla y comunicarla.

- Las interpretaciones son subjetivas: la objetividad se compone de enunciados sometidos a condiciones de enunciación, a la identidad y a las posiciones de los sujetos de la enunciación.

- Los valores son relativos: historia personal y convenciones colectivas.

- El conocimiento es un hecho político: actividad social, relaciones concretas a que dan lugar, relaciones de fuerza, intereses de grupos que defienden determinadas categorías y valores, y cómo se margina a otros grupos.

- La epistemología intercultural invoca la inestabilidad, el mestizaje, el relativismo como fundamento de aproximación. "Las sociedades que se consideran

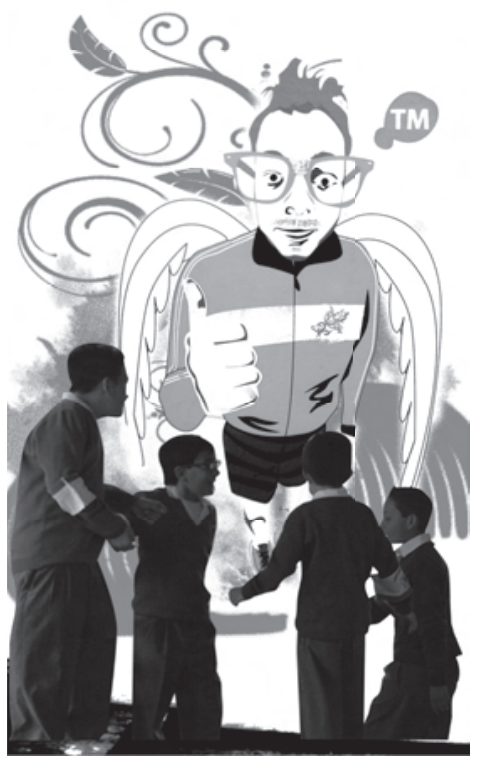

'racionales' soportan con dificultad la ambigüedad y la ambivalencia del devenir mestizo. Estas sociedades desconfían de la pluralidad y buscan imponer las conductas dominantes exclusivas, una visión única del mundo orientando todas las esferas de la vida social" ${ }^{34}$.

- La visión monocultural busca el esencialismo identitario.

- La perspectiva multicultural observa a las identidades como resultado de una evolución histórica, de elecciones políticas y económicas y, sobre todo, de interacciones continuas con otras identidades en el espacio social. 


\section{Las diferencias}

¿Quién tiene el poder para establecer los rasgos distintivos de las razas o de la identidad de las culturas? ¿Quién va a construir esta identidad de la cultura canónica a la que debemos aproximarnos para ser identificados y aceptados como miembros de la comunidad? ¿Cuál es el grado de diferencias que la comunidad nos permitirá antes de estigmatizarnos?

La alternativa es la pluralidad de las identidades. La identidad es una relación dialéctica entre el "yo" y el "otro". No hay identidad sin "el otro". Por consiguiente, al hablar de la identidad propia hay que valorar también la identidad ajena. Como señala Weber, "por lo que hace a la comprensión y a la comunicación debemos darnos cuenta de que el otro, que no pertenece a mi cultura, no piensa obligatoriamente la realidad como yo la conozco, y a la inversa" 35 .

De suerte que una competencia intercultural, es, siguiendo a Weber, la superación de uno mismo, el trabajo con los puntos alternativos de los demás, la habilidad para negociar los significados culturales y para actuar comunicativamente de una forma eficaz de acuerdo con las múltiples identidades de los participantes. Tal vez por esto, la interculturalidad tendría algo así como unas máximas cuya sinergia oscila entre la ficción, la información y la comunicación interpersonal.

- Nada es inmutable.

- No hay posiciones universales.

- Es preciso aceptar el conflicto y la posibilidad de que se hieran los sentimientos.
- Las historias que nos han contado son perversas, pues nuestras identidades se han hecho en oposición a las de otros.

- Nada está cerrado.

- Establecer unos consensos, un orden, un cronograma, no va en contra de la interculturalidad, si ese espacio es, justamente, para defenderla. De lo contrario, la anarquía impediría ver el bosque como "un verde de todos los colores" (Aurelio Arturo). Habrá que intentar, como nos lo recuerda Edgar Morin en una entrevista (El País, 18/7/1992), ser a la vez conservadores y revolucionarios:

Neils Bohr, el gran físico, decía que lo contrario de una verdad vulgar es un error estúpido. Por ejemplo, si yo digo que esa mesa es una mesa y usted dice que es un sillón, usted dice una estupidez. Pero Bohr añadía que lo contrario de una verdad profunda es otra verdad profunda. Hoy día hay que ser a la vez conservador y revolucionario. Conservador en el sentido de que, si se quiere mejorar la humanidad, hay que volver a leer a Sócrates, a Montaigne, a los filósofos y a los poetas. Pero si queremos sobrevivir, conservar la vida, hay que cambiar la organización social y política del planeta. Hay que dar nuevos sentidos a las expresiones conservación y revolución, hay que reconciliar dos verdades profundas. Es una verdad conservadora decir que un ser humano no vive de modo abstracto, necesita tener raíces, pero una vida humana no puede ser plena si no hay una relación rica entre el pasado, el presente y el futuro. El pensamiento simplificador rechaza las contradicciones: el pensamiento complejo, las asume ${ }^{36}$. 


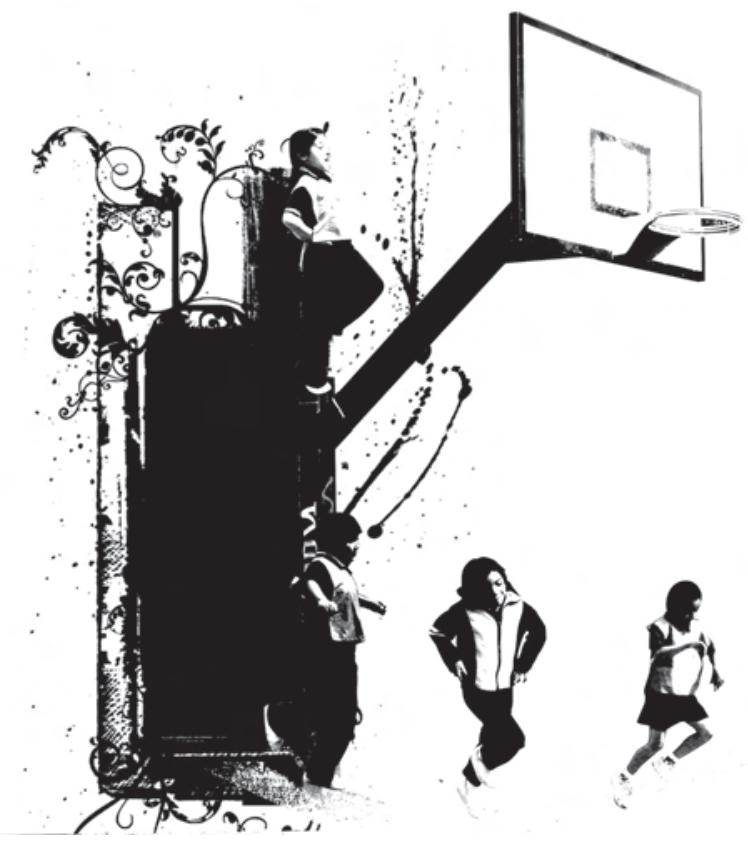

Dos referencias son importantes para justificar la mirada epistemológica desde donde se construirá y tendrá sentido este discurso: la mentalidad interdisciplinaria y la teoría de la frontera.

La mentalidad interdisciplinaria reconfigura los saberes y prácticas que se abrieron camino cuestionando los modelos cosmológicos y teológicos que daban fundamento a las antiguas teorías. El hecho es que la hiperespecialización del saber moderno ha ido disolviéndose en los espacios de conocimiento humano y social, tan interdisciplinarios como transdisciplinarios en la posmodernidad. Estamos no bajo, sino en, el flujo y transición de las disciplinas, ahora nómadas, blandas e incestuosas, que dan origen a múltiples y diversas teorías y metodologías que se revisitan entre sí, polemizando "los grandes relatos". No se expondrán aquí los análisis, revisiones y críticas llevadas a cabo con suficiente contundencia y claridad por Jürgen Habermas, Jean Francois Lyotar, Jacques Derrida, Marshal Berman, Gilles Lipovetsky, Gianni Vattimo, Fredric Jamenson, Slavoj Zîzik y otros. 
Digamos, no obstante, algo más de la interdisciplinariedad; pensémosla más como una actitud mental del investigador y no tanto un método que sistematiza y procesa etapas, pues la pluralidad de voces deben aparecen en sus acuerdos. "El saber es por naturaleza interdisciplinario, pero no progresa sino cuando logra significar entre los discursos plurales que lo componen, razón por la cual regula el surgimiento de disciplinas sobre su campo"37. De suerte que ya no nos remitimos a la concepción griega de saber unificado, sólido, duro, sino que en la modernidad y su espejo posmoderno, ese saber está en construcción, haciéndose continuamente, y es por ello que la interdisciplinariedad protagoniza toda búsqueda.

Si la interdisciplina supera la pluridisciplina, que no es más que suma de saberes, es porque sintetiza conceptos, leyes y aplicaciones. Alejándose del simple encuentro, la interdisciplina afianza diferencias y se instala, o por lo menos lo intenta, como transdisciplina o antidisciplina; es decir, como una zona propia para que habite el saber entre los saberes, pero más que todo, para crear resistencia contra el Estado, la teoría y el poder que se empeñan en poseer el predomino fronterizo.
Es importante comprender el lugar desde el cual se comienzan a mirar los textos audiovisuales contemporáneos, esos que como los filmes, telefilmes, seriados, dramatizados, videoclips y spots publicitarios, invaden hoy los días y los sueños. Los textos audiovisuales que habitan en alcobas, espacios educativos y centros comerciales no sólo sirven para persuadir al espectador a consumir lo que a través de su discurso se comunica o vende, sino además, y es la amenaza más problemática en este momento, que esa pulsión escópica, ese puro ver, se constituye cada vez en consumo si es especular, narcisista, despojado de su relato simbólico. Sin duda, el espectador, consume imagen. Hoy se habla de un comercial con la misma preocupación de cómo se hace de una película, una noticia, la telenovela o el suceso familiar del día. Si hasta hace poco el zapping permitía la evasión de la franja publicitaria al intentar encontrar reposo en alguna otra imagen sujetante, hoy el control, que lo tiene el "perro del Telmex", no escapa a su retórica, mucho menos a su seducción directa e invasiva. 


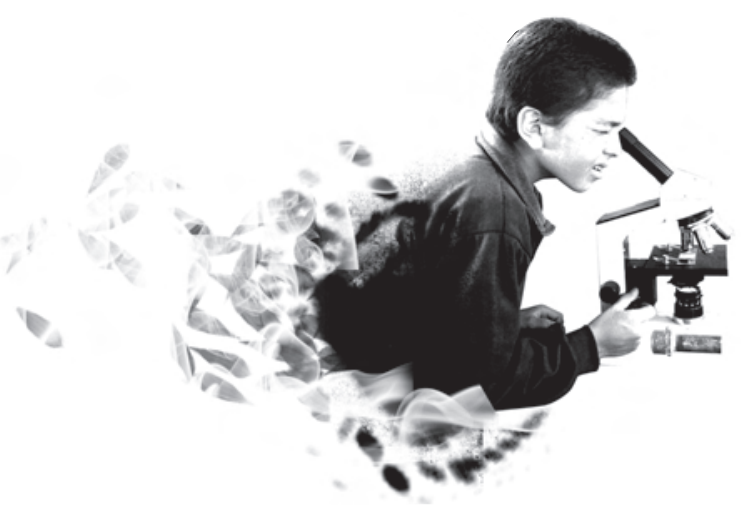

Describamos ahora algunas ideas acerca de la segunda mirada, la de la teoría de la frontera. Los estudios culturales son prueba de ello; sus vínculos con el marxismo, el psicoanálisis, la comunicación y la literatura, generó el campo; hoy los vemos enriquecidos por las reflexiones sobre el multiculturalismo y, a veces, también desdibujado por el pensamiento light. Sin embargo, los límites dan paso a los flujos, el agua rompe los estanques, y se construye una teoría de la frontera desde varios frentes (ideológicos, políticos, artísticos, culturales). Una ambigüedad preocupante surge, sin embargo: si la investigación se afianza cada vez más en el entre, en el estado poroso del flujo y del tránsito, no sucede así con la política cultural de los Gobiernos y de las instituciones educativas que continúan reafirmando los límites; prueba de ello son los nacionalismos, la construcción con ladrillos y alambres de púas entre naciones, las políticas duras contra la inmigración; las fobias; la violencia interracial; la exclusión de las comunidades minoritarias; la virulencia contra los pensadores disidentes; los estatus de ciertas disciplinas, ciertas profesiones, ciertos títulos; los hiperespecialistas y demás.
Se trata de mirar desde la frontera, no como límite sino como cruce y horizonte donde está el Otro, pero además, donde se halla lo Otro. "El giro hacia la frontera - escribe Alejandro Grimson- desplazó las articulaciones de comunidad, cultura y territorio, y cobró relevancia el vínculo, la dinámica y la experiencia. Una nueva importancia adquirirían los conceptos de sujeto, historia y cultura" ${ }^{38}$. Estar en la frontera conlleva por su complejidad, riesgos, y más allá del cruce y el diálogo, hay que estar atento a los conflictos y estigmatizaciones, a las desigualdades y los sometimientos hegemónicos. Es preciso comprender que para cruzar fronteras no implica borrarlas, pues de lo que se trata es de ampliar el concepto de frontera combinando lo geográfico y lo simbólico con lo disciplinario. Los saberes y prácticas fronterizas se producen cuando literatura, antropología e historia, por dar un ejemplo, se combinan con neomarxismo, psicoanálisis, semiótica y feminismo.

Desde ese espacio desterritorializado de nación (sobre todo patriotera), es que esta ubicación surte efectos, pues los estudios sociales y culturales poscoloniales, sobre todo, que cuestionan los territorios nacionales,

38 Grimson, Alejandro. "Disputas sobre las fronteras”, en Michaelsen Scout y Johnson David (Comp.), Teoría de la frontera (los límites de la política cultural), Barcelona, Editorial Gedisa, 2003, p. 15. 
dan pistas para pensar las formas y maneras de abordar los textos culturales, anclando en lo que ocupa, los textos audiovisuales. Los regímenes audiovisuales contemporáneos y sus productos cuya estructura básica es la imagen, tan innovadores como conflictivos, son producciones híbridas: realización internacional, formato devorador de formatos o sin formato (melodrama, reality, tragicomedia, docuficción, etc.), relato manierista que revisa lo clásico y mezcla lo posclásico, contenido multicultural encarnado en figuras así mismo interraciales e internacionales, tecnologías de efectos y precisión, estéticas seductoras: de choque o directas, que experimentan con la retórica, con el kisch y el pastiche. ¿No es aquí donde hoy se juegan los saberes, las prácticas y los poderes de la cultura popular y de masas; donde se negocian identidades y configuran lo sujetos?

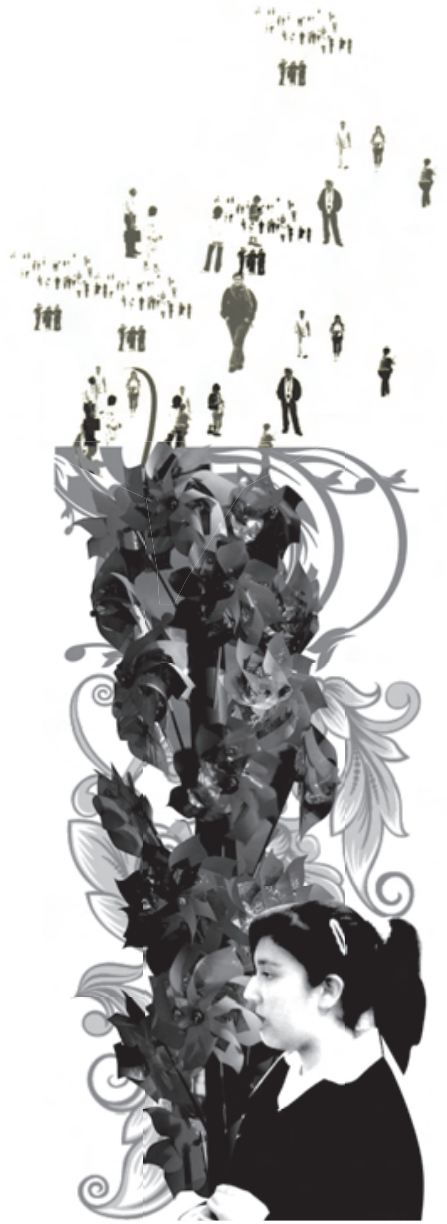




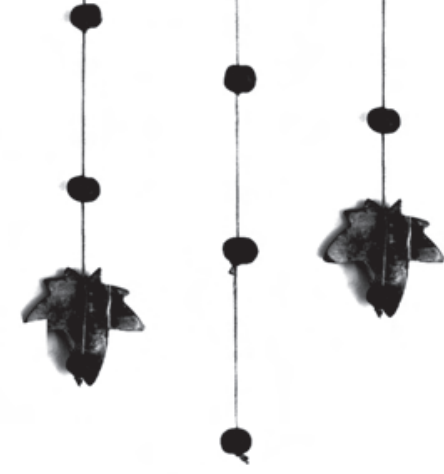

\section{Bibliografía}

Alsina, Miguel Rodrigo. Comunicación intercultural, Barcelona: Anthropos, 1999.

Arheim, Rudolf. Pensamiento visual, $2^{\text {a }}$ edición, Barcelona: Paidós, 1998.

Bertrand, Yves. Théories contemporaines de l'éducation, chrononique sociale, Lyon, 1993.

Bonet, E. y otros. En torno al video, Barcelona: Editorial Gustavo Gilli, 1980.

Bourdieu, Pierre. "Algunas propiedades de los campos”, en Sociología y cultura, México: Editorial Grijalbo, 1984. . Cosas dichas, Barcelona: Gedisa Editorial, 1988. . El sentido práctico, Madrid: Taurus Ediciones, 1991. . Respuestas. Por una antropología reflexiva, México: Editorial Grijalbo, 1995.

. Razones prácticas. Sobre la teoría de la acción, Barcelona: Editorial Anagrama, 1997. - Sobre la televisión, Barcelona, Editorial Anagrama, 1997.

. La distinción, criterio y bases sociales del gusto, Madrid: Taurus Ediciones, 1998. . Intelectuales, política y poder, Buenos Aires: Eudeba, 1999.

Bordieu, Pierre; Passeron, Jean Claude. La reproducción, Madrid, Editorial Popular, 2001.

Buxó, Ma. Jesús. De la investigación audiovisual, Barcelona: Proyecto A Ediciones, 1999.

García Canclini, Néstor. "La sociología de Pierre Bourdieu. Desigualdad cultural y poder simbólico”, en Bourdieu Pierre. Sociología y cultura, México. Editorial Grijalbo, 1984. . Culturas híbridas, México: Editorial Grijalbo, 1989. . Consumidores y ciudadanos, México: Editorial Grijalbo, 1995.

Cassetti, Francesco; Di Chio, Federico. Análisis de la televisión, instrumentos, métodos y prácticas de investigación, Barcelona: Ediciones Paidós, 1999.

Comolli, Annie. Les gestes du savoir. Francia: Universidad de París X, Cine y Ciencias Humanas, 1983.

Daza M., Romelio E. Los medios de comunicación ante el nuevo derecho colombiano, Bopgotá: Inpahu, 1997.

Documents de Travail. Techniques Corporelles du Tournage a la Main, Francia: Universidad de Paris X, 1980. 


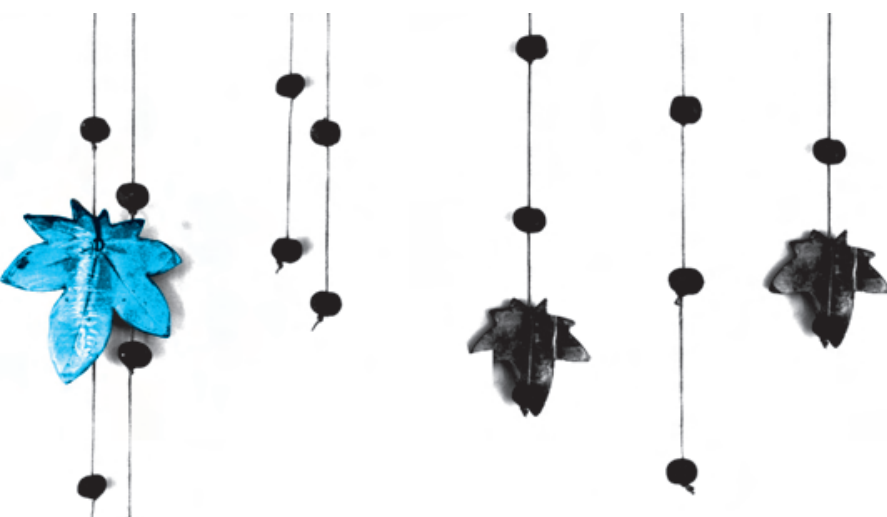

Eco, Umberto. “Crónicas de la aldea global”, en La estrategia de la ilusión, Editorial Lumen, 1990.

Geertz, Clifford. La interpretación de las culturas, Barcelona: Gedisa, 1989.

González Pérez, Marcos. Investigación Interdisciplinaria, Bogotá: Editorial Magisterio, 1998. . Mapa festivo de Bogotá, Bogotá: Intercultura - Secretaría de Gobierno, 2007.

Grimson, Alejandro. "Disputas sobre las fronteras”, en Michaelsen Scout y Johnson David (Comp.), Teoría de la frontera (los límites de la política cultural), Barcelona: Editorial Gedisa, 2003.

Gross, Marie-Marthe; Weiss, Marlise. La pédagogie du projet, París, Armand Colin, 1987.

Heosch, Luc. Cinema et sciences sociales, París: Unesco, 1962.

Huertas, Amparo. La audiencia investigada, Barcelona: Editorial Gedisa, 2002.

Jaramillo Jiménez, Jaime E. Cultura, espacio público y uso del tiempo libre, Bogotá, 1989.

Lacalle, Charo. El espectador televisivo, Barcelona: Editorial Gedisa, 2001.

Londoño, Jorge. Doce reflexiones sobre la televisión y el campus universitario, Bogotá, 2001.

. "De la naranja achatada al ciberespacio", en revista Educación y Ciudad, núm. 3, IDEP, Bogotá, 1997. . "Reseña. Sobre la televisión de Pierre Bourdieu”, en revista Educación y Ciudad, núm. 5, Bogotá: IDEP, 1998. Nacional, 2004

"Las máscaras del diablo", estudio sobre los agentes inculcadores de habitus [CD interactivo], Bogotá: Universidad

Martín-Barbero, Jesús. De los medios a las mediaciones, Barcelona: Editorial Gustavo Gilli, 1989.

"Heredando el futuro. Pensar la educación desde la comunicación”, en revista Nómadas, núm. 5, Bogotá: Fundación Universidad Central, 1996.

. "Retos de la televisión a la educación y del país a la televisión", en Memorias Segundo encuentro nacional de Televisión educativa, Cali: UVTV, 1997.

“La televisión o el mal de ojo de los intelectuales”, en revista Número, núm. 10, Bogotá, 1996.

Martín-Barbero, Jesús; Rey, Germán. Los ejercicios del ver, Barcelona: Editorial Gedisa, 1999.

Morin, Edgar. La cabeza bien puesta, Buenos Aires: Nueva Visión, 1999.

Pérez Tornero, José. El desafío educativo de la televisión, Barcelona: Ediciones Paidós, 1994. 
